\title{
PERSEPSI DAN PARTISIPASI MASYARAKAT DALAM PENGEMBANGAN LUMBUNG PANGAN DI KABUPATEN LAMPUNG BARAT
}

\author{
(Community's Perception and Participation in Developing Food Barn in Lampung Barat District)
}

Kholiq $^{1}$, Hardinsyah², dan M.D. Djamaludin ${ }^{3}$

${ }^{1}$ Program Studi Manaj emen Ketahahan Pangan (MKP), Sekolah Pascasarjana, IPB.
2 Departemen Gizi Masyarakat, Fakultas Ekologi Manusia (FEMA), IPB
Tel: 0251-8628304/ 8621258; Fax: 0251-8625846/ 8622276
${ }^{3}$ Departemen IImu Keluarga dan Konsumen, Fakultas Ekologi Manusia (FEMA), IPB
Tel: 0251-8628303/ 8627432; Fax: 0251-8625846/8622276

ABSTRACT

Community's perception and participation is necessary to be noticed in the effort of developing food barn in rural area. The objective of this study were to: 1) analyze community's perception about food barn in Lampung Barat District, 2) inventory factors that influence community's participation in developing food barn in Lampung Barat District, 3) formulate model and strategy in developing participative food barn to reach food security in Lampung Barat District. This research was conducted by using cross sectional design and descriptive analysis approach. The location was chosen by using purposive sampling which were in Tribudi Syukur Village, Sumberjaya Subdistrict and Buay Nyerupa Village, Sukau Subdistrict. The selection was based on consideration that these villages has different implementation performance of food barn according to the assessment from Food Crops and Horticulture Office in Lampung Barat District. The result of the research shows that the community's perception category, represented by farmer as sample, based on total perception variable score between Tribudi Syukur and Buay Nyerupa, is different. The general condition of the community (like age, education level, income, etc.) do not have correlation with its perception about food barn. The community's participation in food barn category, represented by farmer as sample, based on total participation variable score between Tribudi Syukur and Buay Nyerupa, is also different. There is correlation between community's perception about food barn and its participation in developing food barn activity. The factors that influence community's participation in developing food barn are tradition to store food by the community, the existence of farmer group, community's perception about food barn, the existence of regional governmental structural institution in Food Security, regulation or guidance which support food barn developing, governmental program which support food barn development, the development of food market and trading, condition of region which potentially food insecure. The priority of strategy in developing participative food barn based on the result of SWOT analysis that possible to be conducted are 1) develop community's perception to not relying on market in accessing food, 2) develop perception and community participation empowerment in creating and developing food barn based on regional condition, 3) maintain and build community's tradition of storing food from self food storing to collective food storing (in group).

Keywords: food barn, perception, participation, community.

\section{PENDAHULUAN}

Ketahanan pangan merupakan salah satu prasyarat dasar yang harus dimiliki oleh daerah disamping prasyarat lainnya dalam rangka mewujudkan kesejahteraan masyarakat. Ketahanan pangan terdiri dari tiga subsistem utama yakni ketersediaan, distribusi dan konsumsi. jika ketiga subsistem tersebut dapat dikelola dengan baik di suatu wilayah maka tercapailah yang disebut dengan kondisi wilayah yang tahan pangan dan sebaliknya bila hal tersebut tidak dapat diwujudkan maka akan terjadi kondisi yang rawan pangan. Kondisi ketahanan pangan menentukan status gizi individu dalam masyarakat yang pada akhirnya berpengaruh terhadap kualitas sumber daya manusia.

Lampung Barat bila ditinjau dari kondisi wilayah, sosial, ekonominya dikaitkan dengan konsep ketahanan pangan dapat dikatakan berada pada kondisi yang kurang menguntungkan. Kondisi tersebut yang bila tidak diantisipasi 
sejak awal sangat berpotensi terjadi rawan pangan. Beberapa kondisi yang kurang menguntungkan tersebut antara lain ialah 1) Lampung Barat mempunyai luas wilayah 495040 ha atau $4950.40 \mathrm{~km}^{2}$, tetapi hanya sekitar $22 \%$ dari luasan tersebut yang dapat diperuntukkan menjadi kawasan budi daya (pertanian dan non pertanian), permukiman, serta untuk fasilitas infrastruktur wilayah, sedangkan selebihnya, sekitar 78\% merupakan kawasan lindung yang terdiri atas wilayah Taman Nasional Bukit Barisan Selatan dan beberapa Register Hutan Lindung; 2) Kabupaten Lampung Barat juga berada pada wilayah yang rawan bencana terutama gempa bumi karena berada pada zona patahan lapisan bumi yang dikenal dengan zona sesar semangko; 3) Ditinjau dari aspek demografi, jumlah penduduk Kabupaten Lampung Barat adalah 410848 jiwa dengan jumlah rumah tangga (RT) sebanyak 107194 (BPS, 2007). Dari jumlah penduduk dan rumah tangga tersebut terdapat 49506 rumah tangga miskin (RTM) atau sekitar $46.18 \%$ 4) Selain itu meskipun sebagian besar mata pencaharian penduduk Kabupaten Lampung Barat di sektor pertanian (petani) namun mayoritas usaha taninya adalah pada perkebunan (terutama komoditas kopi) yang merupakan komoditas tahunan, sehingga ada rentang waktu yang relatif lama bagi petani tersebut menunggu dan menikmati hasilnya.

Dalam upaya pengembangan cadangan pangan, daerah-daerah dihimbau untuk menghidupkan kembali lumbung pangan, hal ini ditunjukkan dengan dikeluarkannya produk hukum pemerintah yakni Keputusan Menteri Dalam Negeri Nomor 6 Tahun 2001 tentang Pengembangan Lumbung Pangan Masyarakat Desa / Kelurahan. Dalam produk hukum yang dikeluarkan pemerintah tersebut secara implisit mengisyaratkan pentingnya partisipasi masyarakat agar lumbung pangan masyarakat kembali tumbuh dan berkembang. Namun untuk memberdayakan dan meningkatkan partisipasi masyarakat tersebut ada indikasi terkait dengan persepsi masyarakat terhadap lumbung pangan tersebut.

Penelitian ini bertujuan untuk: 1) Menganalisis persepsi masyarakat tentang lumbung pangan di Kabupaten Lampung Barat; 2) Menginventarisasi faktor-faktor yang mempengaruhi partisipasi masyarakat dalam pengembangan lumbung pangan di Kabupaten Lampung Barat; 3) Merumuskan model lumbung pangan dan strategi pengembangannya secara partisipatif untuk mendukung ketahanan pangan Kabupaten Lampung Barat.

\section{METODE PENELITIAN}

\section{Desain, Tempat, dan Waktu Penelitian}

Penelitian ini menggunakan desain cross sectional study dengan pendekatan descriptive analysis. Penelitian dilakukan di Kabupaten Lampung Barat Provinsi Lampung yang pengambilan sampelnya secara purposive di Desa (Pekon) Tribudi Syukur Kecamatan Sumberjaya dan Pekon Buay Nyerupa Kecamamatan Sukau. Penentuan lokasi ini didasarkan pada hasil konsultasi dengan Dinas Tanaman Pangan dan Hortikultura Kabupaten Lampung Barat dengan pertimbangan bahwa di kedua lokasi tersebut terdapat kegiatan lumbung pangan dalam wadah kelompok tani. Waktu pelaksanaan yakni pada bulan Oktober sampai dengan bulan November 2008.

\section{Penarikan Contoh}

Sampel penelitian ini adalah petani, tokoh masyarakat, dan pejabat (petugas) di tingkat kecamatan dan kabupaten. Petani dari masing-masing desa dipilih secara acak sebanyak 45 (empat puluh lima) orang ditambah tokoh masyarakat sebanyak 3 (tiga) orang. Selain itu juga ditentukan sampel pejabat (petugas) terkait bidang pemberdayaan masyarakat dan ketahanan pangan baik di tingkat kecamatan masing-masing 2 (dua) orang dan dari tingkat kabupaten 3 (tiga) orang. Sehingga total sampel adalah 103 (seratus tiga) orang.

\section{Jenis dan Cara Pengumpulan Data}

Data yang digunakan meliputi data sekunder dan primer. Data sekunder meliputi luas baku lahan pertanian, jumlah petani, tingkat produktivitas, keberadaan lumbung pangan, jumlah pasar. Data primer yang dikumpulkan adalah dari:

a. Petani sampel meliputi data demografi/ kondisi fisik petani (umur, pendidikan terakhir, Iuas Iahan sawah yang dikuasai, produksi dan produktivitas padi sawah, jumlah anggota keluarga, ada atau tidaknya pekerjaan sampingan, dan besar pendapatan per kapita per bulan), data persepsi terhadap lumbung pangan (pandangan tentang perlu atau tidaknya menyimpan persediaan pangan, pengenalan dan pandangan/ penilaian terhadap lumbung pangan, kepercayaan terhadap sistem lumbung pangan dan keyakinan untuk mengembangkannya), dan data partisipasi dalam kegiatan dan pengembangan lumbung pangan (setuju atau tidak terhadap keberadaan lumbung pangan, ikut memanfaatkan lumbung pangan atau tidak, 
keikutsertaan dalam kegiatan pengambilan keputusan di kelompok lumbung pangan atau tidak, dan keikutsertaan dalam pengeIolaan lumbung pangan).

b. Tokoh masyarakat di lokasi pengambilan sampel meliputi data persepsi dan partisipasi yang mendukung data persepsi dan partisipasi petani sampel serta faktor-faktor yang mempengaruhi partisipasi masyarakat dalam hal kegiatan dan pengembangan lumbung pangan.

c. Pejabat/ petugas yang berkaitan dengan bidang ketahanan pangan dan pemberdayaan masyarakat baik pada tingkat kecamatan lokasi pengambilan sampel maupun pada tingkat kabupaten meliputi data faktor-faktor yang mempengaruhi partisipasi masyarakat dalam kegiatan dan pengembangan lumbung pangan serta pandangan mengenai strategi yang dapat ditempuh dalam pengembangan lumbung pangan secara partisipatif.

Pengumpulan data sekunder dilakukan dari instansi terkait, sedangkan data primer dikumpulkan dengan cara wawancara terstruktur menggunakan kuesioner terhadap sampel petani dan wawancara mendalam (indepth interview) terhadap tokoh masyarakat dan petugas/ pejabat.

\section{Pengolahan dan Analisis Data}

Data sekunder yang diperoleh disajikan secara informatif dalam bentuk tabel dan gambar/diagram. Data primer petani sampel berdasarkan karakteristiknya (umur, pendidikan terakhir, luas lahan sawah yang dikuasai, produktivitas padi sawahnya, jumlah anggota keluarga, dan pendapatan per kapita/bulan) disajikan dalam bentuk tabel dan dianalisis sesuai frekuensinya pada kedua pekon lokasi pengambilan sampel. Data karakteristik petani sampel yang sangat beragam (umur, luas Iahan sawah, produktivitas padi sawah, jumlah anggota keluarga, dan pendapatan per kapita per bulan) dikategorikan berdasarkan interval atau merujuk kategori yang telah dibakukan secara umum.

Persepsi petani sampel terhadap lumbung pangan diukur dari hasil jawaban kuesioner tentang variabel persepsi yang ditanyakan. Data petani sampel berdasarkan kelompok variabel persepsi terhadap lumbung pangan tersebut disajikan dalam bentuk tabel dan dianalisis sesuai frekuensinya pada kedua lokasi penelitian.

Untuk memperoleh kategori persepsi petani sampel terhadap lumbung pangan dilaku- kan skoring terhadap masing-masing jawaban kuesioner sesuai variabel persepsi yang ditanyakan. Skoring terhadap jawaban kuesioner tersebut dilakukan dengan cara apabila terdiri dari dua jawaban (misalnya jawaban ya atau tidak, untuk jawaban ya diberi skor 2 dan untuk jawaban tidak diberi skor 1) sedangkan apabila jawaban terdiri dari tiga jawaban (misalnya setuju, ragu-ragu, dan tidak setuju, untuk jawaban setuju diberi skor 3, ragu-ragu diberi skor 2, dan tidak setuju diberi skor 1). Jumlah skor untuk masing-masing responden merupakan nilai persepsi responden tersebut. Terhadap nilai persepsi tersebut dilakukan pengkategorian sesuai interval yang diperoleh dari selisih nilai tertinggi dengan nilai terendah dibagi dengan jumlah kategori yang ditentukan sehingga diperoleh kategori persepsi terhadap lumbung pangan yang terdiri atas kurang, sedang, dan baik.

Data partisipasi petani sampel dalam kegiatan dan pengembangan lumbung pangan juga diukur dari jawaban kuesioner berdasarkan variabel partisipasi yang ditanyakan. Data partisipasi berdasarkan variabel partisipasi tersebut juga disajikan dalam bentuk tabel dan dianalisis sesuai frekuensinya. Untuk memperoleh kategori partisipasi petani sampel dalam kegiatan dan pengembangan lumbung pangan juga dilakukan skoring sebagaimana yang dilakukan pada variabel persepsi, sehingga diperoleh kategori partisipasi petani sampel yang terdiri atas kurang, sedang, dan baik.

Analisis data dilakukan secara deskriptif (descriptive analysis) melalui cara pengelompokkan dan tabulasi silang antar variabel dengan menggunakan alat bantu program komputer microsoft excell dan SPSS. Untuk merumuskan strategi pengembangan lumbung pangan secara partisipatif sesuai kondisi hasil penelitian dilakukan dengan analisis lingkungan strategis yakni faktor eksternal yang terdiri atas kekuatan (Strengths) dan kelemahan (Weaknesses) serta faktor internal yang terdiri atas peluang (Oportunities) dan Ancaman (Threats) atau analisis SWOT.

\section{HASIL DAN PEMBAHASAN}

Keadaan Lumbung Pangan di Kabupaten Lampung Barat

Keberadaan lumbung pangan di Kabupaten Lampung Barat pada umumnya adalah pada kelompok tani. Kegiatan lumbung pangan merupakan bagian dari sistem kegiatan kelompok tani. Adapun jumlah kelompok tani 
dan kegiatan lumbung pangannya pada tingkat kabupaten dan sesuai lokasi penelitian adalah tertera pada Tabel 1.

Tabel 1. J umlah Kelompok Tani dan Kelompok Tani yang melaksanakan Lumbung Pangan per Kecamatan di Kabupaten Lampung Barat

\begin{tabular}{clrc}
\hline No. & \multicolumn{1}{c}{ Kecamatan } & $\begin{array}{c}\text { Jumlah } \\
\text { Kelompok } \\
\text { Tani }\end{array}$ & $\begin{array}{c}\text { Jumlah } \\
\text { Kelompok } \\
\text { Tani yang } \\
\text { Melaksanakan } \\
\text { Lumbung } \\
\text { Pangan }\end{array}$ \\
\hline 1 Sumberjaya & 106 & 9 \\
2 Gedung Surian & 47 & 7 \\
3 Way Tenong & 107 & 2 \\
4 Belalau & 82 & - \\
5 Batu Brak & 69 & 4 \\
6 Sekincau & 100 & - \\
7 Suoh & 71 & 7 \\
8 Balik Bukit & 56 & 2 \\
9 Sukau & 93 & 2 \\
10 Pesisir Selatan & 110 & 5 \\
11 & Bengkunat & 28 & - \\
12 & Pesisir Tengah & 44 & 1 \\
13 Karya Penggawa & 66 & - \\
14 Pesisir Utara & 70 & 1 \\
15 Lemong & 38 & - \\
16 & Ngambur & 85 & - \\
17 Bengkunat Belimbing & 31 & 1 \\
\hline
\end{tabular}

Sumber: Dinas Tanaman Pangan dan Hortikultura Kab. Lampung Barat (2007)

Kegiatan lumbung pangan di Pekon Tribudi Syukur ada pada Kelompok Tani Triguna IV, V, sedangkan di Bekon Buay Nyerupa ada pada Kelompok Tani Pancaran Muda. Berdasarkan informasi dari Dinas Tanaman Pangan dan Hortikultura Kabupaten Lampung Barat, bahwa kegiatan lumbung pangan di kedua pekon tersebut pernah mendapat bantuan pembinaan dari pemerintah. Lumbung pangan di Tribudi Syukur pada tahun 2008 mendapat bantuan pembinaan berupa bantuan fisik bangunan lumbung pangan 1 unit, sedangkan di Buay Nyerupa pada tahun 2006 pernah mendapat bantuan satu unit mesin penggiling padi (RMU). Kondisi tersebut menjadi pertimbangan penentuan lokasi dalam penelitian ini.

Rata-rata umur petani sampel ialah 50.07 tahun untuk Tribudi Syukur dan 49.78 tahun untuk Buay Nyerupa. Kondisi umur ini menurut Papalia dan Olds dalam Basri (2006) tergolong pada kategori umur dewasa madya (41 sampai dengan 65 tahun). Pendidikan terakhir petani sampel mayoritas SD untuk Tribudi Syukur dan SMP untuk Buay Nyerupa.
Luasan Iahan sawah yang dikuasai sampel petani rata-rata 0.52 ha untuk Tribudi Syukur dan 0.60 untuk Buay Nyerupa, Iuasan ini relatif sama dengan luas penguasaan Iahan sawah di daerah lain seperti di OKI Sumatera Sumatera Selatan yakni antara 0.25 ha sampai dengan 0.70 ha (Hutapea dan Bamualim, 2004). Produktivitas usaha tani padi sawah yang dicapai rata-rata 3.96 ton per ha untuk Tribudi Syukur dan 3.80 ton per ha untuk Buay Nyerupa, capaian produktifitas padi sawah ini masih di bawah rata-rata capaian produktifitas tingkat Kabupaten Lampung Barat yang telah ditetapkan 4.2 ton per ha dan juga masih dibawah produktivitas padi sawah rata-rata nasional yang sebesar 4.8 ton per ha (BPS dan Ditjen TP, 2008).

J umlah anggota keluarga petani sampel adalah antara 3 sampai dengan 4 orang baik di Tribudi Syukur maupun di Buay Nyerupa. Pendapatan/ kapita/ bulan masyarakat petani yang diwakili responden di Tribudi Syukur (rata rata Rp. 663 796) lebih tinggi dari ada Pekon Buay Nyerupa (rata-rata Rp. 375 652), namun demikian rata-rata pendapatan/kapita/bulan ini masih di atas kategori keluarga miskin sebagaimana yang telah ditetapkan oleh BPS (2008) bahwa kategori keluarga miskin untuk wilayah Provinsi Lampung kategori miskin pedesaan Rp. 145634 per kapita per bulan dan perkotaan Rp. 187423.

Karakteristik demografi petani sampel pada penelitian ini yang meliputi umur, pendidikan terakhir, produktivitas lahan sawah, jumlah anggota keluarga petani, dan pendapatan/ kapita/ bulan secara umum untuk kedua lokasi penelitian (Tribudi Syukur dan Buay Nyerupa) tidak berbeda berdasarkan hasil uji Chisquare (Asymp. Sig. (2-sided) lebih dari 0.05) kecuali untuk variabel luas lahan sawah yang dikuasai nilai Asymp. Sig. (2-sided) sebesar 0.041 . Adapun sebaran petani sampel berdasarkan karakteristik demografi dan hasil uji Chi-square sebagaimana tertera pada Tabel 2.

\section{Persepsi Masyarakat terhadap Lumbung Pa- ngan}

Pandangan masyarakat tentang perlu atau tidaknya menyimpan persediaan pangan merupakan variabel kondisi sosial di masyarakat yang dapat digunakan untuk menjajaki persepsinya terhadap lumbung pangan. Dalam hal ini dapat diketahui apakah di masyarakat tersebut memandang penting atau tidak menyimpan persediaan pangan untuk mengantisipasi kebutuhan pangan untuk waktu yang akan datang baik secara individual, keluarganya maupun 
Tabel 2. Sebaran Petani Sampel di Pekon Tribudi Syukur dan Pekon Buay Nyerupa berdasarkan Karakteristik Demografi

\begin{tabular}{|c|c|c|c|c|c|c|}
\hline \multirow{2}{*}{ No. } & \multirow{2}{*}{ Variabel } & \multirow{2}{*}{ Kategori } & \multicolumn{2}{|c|}{ Tribudi Syukur } & \multicolumn{2}{|c|}{ Buay Nyerupa } \\
\hline & & & $\mathbf{n}$ & $\%$ & n & $\%$ \\
\hline \multirow[t]{7}{*}{1} & Umur: & & & & & \\
\hline & 18 s.d. 40 th & Dewasa Muda & 2 & 4.4 & 4 & 8.9 \\
\hline & 40 s.d 65 th & Dewasa Madya & 43 & 95.6 & 41 & 91.1 \\
\hline & \multicolumn{2}{|l|}{ Total } & 45 & 100.0 & 45 & 100.0 \\
\hline & \multicolumn{2}{|c|}{ Chi square (Asymp. Sig. (2-sided)) } & & & & 0.398 \\
\hline & Variahel & Kategori & \multicolumn{2}{|c|}{ Tribudi Syukur } & \multicolumn{2}{|c|}{ Buay Nyerupa } \\
\hline & Vallavel & Kategur & $\mathbf{n}$ & $\%$ & $\mathrm{n}$ & $\%$ \\
\hline \multirow[t]{5}{*}{2} & Pendidikan Terakhir: & SD & 17 & 37.8 & 11 & 24.4 \\
\hline & & SMP & 13 & 28.9 & 17 & 37.3 \\
\hline & & SLTA & 14 & 31.1 & 15 & 33.3 \\
\hline & & Di atas SLTA & 1 & 2.2 & 2 & 4.4 \\
\hline & Total & & 45 & 100.0 & 45 & 100.0 \\
\hline & Chi square (Asymp. & g. (2-sided)) & & & & 0.535 \\
\hline \multirow[t]{7}{*}{3} & Penguasaan & & & & & \\
\hline & Lahan Sawah & & & & & \\
\hline & (na): 0.25 s.d. 0.69 & Sempit & 37 & 822 & 28 & 62.2 \\
\hline & - $\quad 0.70$ s.d. 1.13 & Sedang & 7 & 15.6 & 17 & 37.8 \\
\hline & - $\quad 1.14$ s.d 1.57 & Cukup Luas & 0 & 0.0 & 0 & 0.0 \\
\hline & - Di atas 1.57 & Luas & 1 & 2.2 & 0 & 0.0 \\
\hline & Total & & 45 & 100.0 & 45 & 100.0 \\
\hline \multirow{7}{*}{4} & Chi square (Asymp. & g. (2-sided)) & & & & 0.041 \\
\hline & Produktivitas & & & & & \\
\hline & (ton/ha): & & & & & \\
\hline & - $\quad<4.2$ & Di bawah standar & 36 & 80.0 & 37 & 82.2 \\
\hline & - $\quad 4.2$ & Standar Kab. & 9 & 20.0 & 8 & 17.8 \\
\hline & - $\quad>4.2$ & Di atas Standar & 0 & 0.0 & 0 & 0.0 \\
\hline & Total & & 45 & 100.0 & 45 & 100.0 \\
\hline \multirow{5}{*}{5} & Chi square (Asymp. S & (2-sided)) & & & & 0.339 \\
\hline & J umlah Anggota Keluarga & a. $2-3$ & 26 & 57.8 & 18 & 40.0 \\
\hline & Petani (J iwa) & b. $4-5$ & 18 & 40.0 & 27 & 60.0 \\
\hline & & c. $6-7$ & 1 & 2.2 & 0 & 0.0 \\
\hline & Total & & 45 & 100.0 & 45 & 100.0 \\
\hline \multirow{7}{*}{6} & Chi square (Asymp. $\subseteq$ & y. (2-sided)) & & & & 0.119 \\
\hline & Pendapatan per kapita & & & & & \\
\hline & $\begin{array}{l}\text { per bulan } \\
\text { (Rp.) }\end{array}$ & $\begin{array}{l}\text { a. Miskin } \\
\text { ( S.d. } 145634 \text {,) }\end{array}$ & 0 & 0.0 & 0 & 0.0 \\
\hline & & a. Tidak Miskin & 45 & 100.0 & 45 & 100.0 \\
\hline & & $\begin{array}{c}\text { (di atas } 145 \\
634 \text { ) }\end{array}$ & & & & \\
\hline & Total & & 45 & 100.0 & 45 & 100.0 \\
\hline & Chi square (Asymp. S & g. (2-sided)) & Tak dapa & ung karen & gori pen & konstan \\
\hline
\end{tabular}

secara berkelompok. Dari penelitian ini ternyata baik di Pekon Tribudi Syukur atau pun di Pekon Buay Nyerupa diperoleh hasil yang tidak berbeda. Seluruh petani sampel di dua lokasi tersebut mempunyai pandangan yang sama yaitu perlu menyimpan bahan pangan (padi atau beras) untuk persediaan bagi keluarganya selama waktu tertentu ke depan sambil menunggu musim panen berikutnya. Tradisi masyarakat petani yang demikian ini memang terjadi di kalangan petani pedesaan di Indonesia sebagaimana yang dikemukakan Saliem, et al., (2005) bahwa tradisi masyarakat petani melakukan cadangan pangan secara sendiri-sendiri masih relatif kuat terutama pada kalangan petani dengan luas sawah garapan yang sempit.
Persepsi terhadap lumbung pangan juga dilihat dari apakah masyarakat mengenal lumbung pangan atau tidak, kemudian bagaimana pandangan ataupun penilaiannya terhadap lumbung pangan tersebut. Untuk mengetahui pandangan ataupun penilaian terhadap lumbung pangan dilihat dari apakah masyarakat memandang lumbung pangan tersebut bermanfaat atau tidak, serta apakah lumbung pangan tersebut diperlukan atau tidak. Selain dari itu persepsi masyarakat terhadap lumbung pangan juga dapat diketahui dari bagaimana kepercayaannya (trust) terhadap sistem lumbung pangan dan keyakinan untuk mengembangkannya. Kepercayaan (trust) terhadap sistem lumbung pangan dan keyakinan untuk mengembangkannya dapat diketahui dari penda- 
patnya apakah percaya atau tidak terhadap sistem yang berlaku di lumbung pangan, pendapatnya apakah lumbung pangan bisa dikembangkan atau tidak, dan pendapatnya apakah dalam mengembangkan lumbung pangan tersebut harus dibantu pemerintah atau tidak.

Nilai persepsi masyarakat yang diwakili petani sampel berdasarkan hasil total skor masing-masing variabel persepsi petani sampel terhadap lumbung pangan dikelompokkan dalam kategori kurang, sedang dan baik. Adapun sebaran petani sampel berdasarkan kategori persepsi masyarakat terhadap lumbung pangan untuk Tribudi Syukur adalah 6.7\% kurang, $15.6 \%$ sedang, dan $77.8 \%$ baik, sedangkan untuk Buay Nyerupa 24.4\% kurang, 62.2\% sedang, dan $13.3 \%$ baik. Hasil uji Chi-square menunjukkan bahwa persepsi terhadap lumbung pangan antara petani sampel di Tribudi Syukur dengan di Buay Nyerupa berbeda (nilai Asymp.Sig. (2-sided) kurang dari 0.05). Kondisi tersebut sebagaimana tertera pada Tabel 3.

Tabel 3. Sebaran Petani Sampel di Pekon Tribudi Syukur dan Buay Nyerupa berdasarkan Kategori Persepsi terhadap Lumbung Pangan.

\begin{tabular}{lrrrr}
\hline \multirow{2}{*}{$\begin{array}{c}\text { Kategori Persepsi thd. } \\
\text { Lumbung Pangan }\end{array}$} & \multicolumn{4}{c}{ Pekon } \\
\cline { 2 - 5 } & \multicolumn{1}{c}{ Tribudi Syukur } & \multicolumn{2}{c}{$\begin{array}{c}\text { Buay } \\
\text { Nyerupa }\end{array}$} \\
\cline { 2 - 5 } & $\mathbf{n}$ & \multicolumn{1}{c}{$\%$} & $\mathbf{n}$ & $\%$ \\
\hline - Kurang & 3 & 6.7 & 11 & 24.4 \\
- Sedang & 7 & 15.6 & 28 & 62.2 \\
- Baik & 35 & 77.8 & 6 & 13.3 \\
Total & 45 & 100.0 & 45 & 100.0 \\
\hline Chi square (Asymp. Sig. (2-sided)) & & & 0.000 \\
\hline
\end{tabular}

Hubungan antara Kondisi Umum dengan Persepsi Masyarakat terhadap Lumbung Pangan

Dalam penelitian ini diketahui bahwa kondisi umum masyarakat (umur, pendidikan terakhir, besar pendapatan, dan lainnya) tidak mempengaruhi persepsinya terhadap lumbung pangan (berdasarkan hasil analisis sebagaimana tertera pada Tabel 5). Hal ini dapat dipahami karena pada dasarnya pembentukan persepsi seseorang itu lebih dipengaruhi oleh faktor pribadi antara lain penerimaan informasi, pengalaman, cakrawala, dan pengetahuannya terhadap obyek, bukannya faktor-faktor fisik yang ada pada seseorang (Mar'at, 1984).

\section{Partisipasi Masyarakat dalam Kegiatan dan Pengembangan Lumbung Pangan}

Partisipasi masyarakat dalam kegiatan dan pengembangan lumbung pangan dapat diketahui dari beberapa indikator antara lain dalam hal keikutsertaan mayarakat dalam memanfaatkan, keikutsertaan dalam musyawarah dan pengambilan keputusan, serta keikutsertaan dalam pengelolaan lumbung pangan tersebut. Beberapa indikator tersebut dapat dijadikan variabel untuk memperoleh kondisi tingkat partisipasi masyarakat yang diwakili petani sampel dalam kegiatan dan pengembangan lumbung pangan yang ada. Berdasarkan variabel ikut serta memanfaatkan atau tidak, ikut serta dalam proses pengambilan keputusan (musyawarah) atau tidak, dan ikut serta dalam pengelolaan baik sebagai anggota ataupun pengurus atau tidak ikut mengelola terhadap lumbung pangan dari masyarakat petani terhadap lumbung pangan yang ada di wilayahnya dalam penelitian ini diperoleh hasil bahwa antara petani sampel di Tribudi Syukur dengan di Buay Nyerupa terdapat perbedaan.

Nilai partisipasi masyarakat yang diperoleh dari skoring terhadap variabel partisipasi masyarakat di atas di kategorikan kurang, sedang, dan baik. Adapun sebaran petani sampel berdasarkan kategori partisipasinya terhadap keberadaan lumbung pangan di dua pekon adalah bahwa di Tribudi Syukur adalah 28.9\% kurang, $11.1 \%$ sedang, dan $60.0 \%$ baik, sedangkan untuk Buay Nyerupa 68.9\% kurang, 17.8\% sedang, dan 13.3\% baik. Berdasarkan kategori partisipasi masyarakat tersebut dapat diketahui juga bahwa terdapat perbedaan antara Tribudi Syukur dengan buay Nyerupa (sesuai hasil uji chi square), hal ini sebagaimana ditunjukkan pada Tabel 4.

Tabel 4. Sebaran Petani Sampel di Pekon Tribudi Syukur dan Buay Nyerupa berdasarkan Kategori Partisipasi terhadap terhadap Lumbung Pangan

\begin{tabular}{lrrrr}
\hline \multirow{2}{*}{$\begin{array}{c}\text { Kategori } \\
\text { Partisipasi }\end{array}$} & \multicolumn{4}{c}{ Pekon } \\
\cline { 2 - 5 } & \multicolumn{1}{c}{ Tribudi Syukur } & \multicolumn{1}{c}{ Buay Nyerupa } \\
\cline { 2 - 5 } & $\mathbf{n}$ & $\%$ & $\mathbf{n}$ & $\%$ \\
\hline - kurang & 13 & 28.9 & 31 & 68.9 \\
- Sedang & 5 & 11.1 & 8 & 17.8 \\
- Baik & 27 & 60.0 & 6 & 13.3 \\
\hline Total & 45 & 100.0 & 45 & 100.0 \\
Chi square (Asymp. Sig. (2-sided)) & & 0.000 \\
\hline
\end{tabular}

\section{Hubungan antara Persepsi dengan Partisipasi Masyarakat dalam Kegiatan dan Pengemba- ngan Lumbung Pangan}

Berdasarkan beberapa variabel partisipasi masyarakat petani, diketahui bahwa secara umum kondisi partisipasi tersebut dalam pengembangan lumbung pangan antara Pekon Tribudi Syukur dengan Pekon Buay Nyerupa berbeda. Untuk mengetahui apakah kondisi 
Tabel 5. Hubungan antara Variabel Kondisi Umum Petani Sampel terhadap Persepsinya tentang Lumbung Pangan

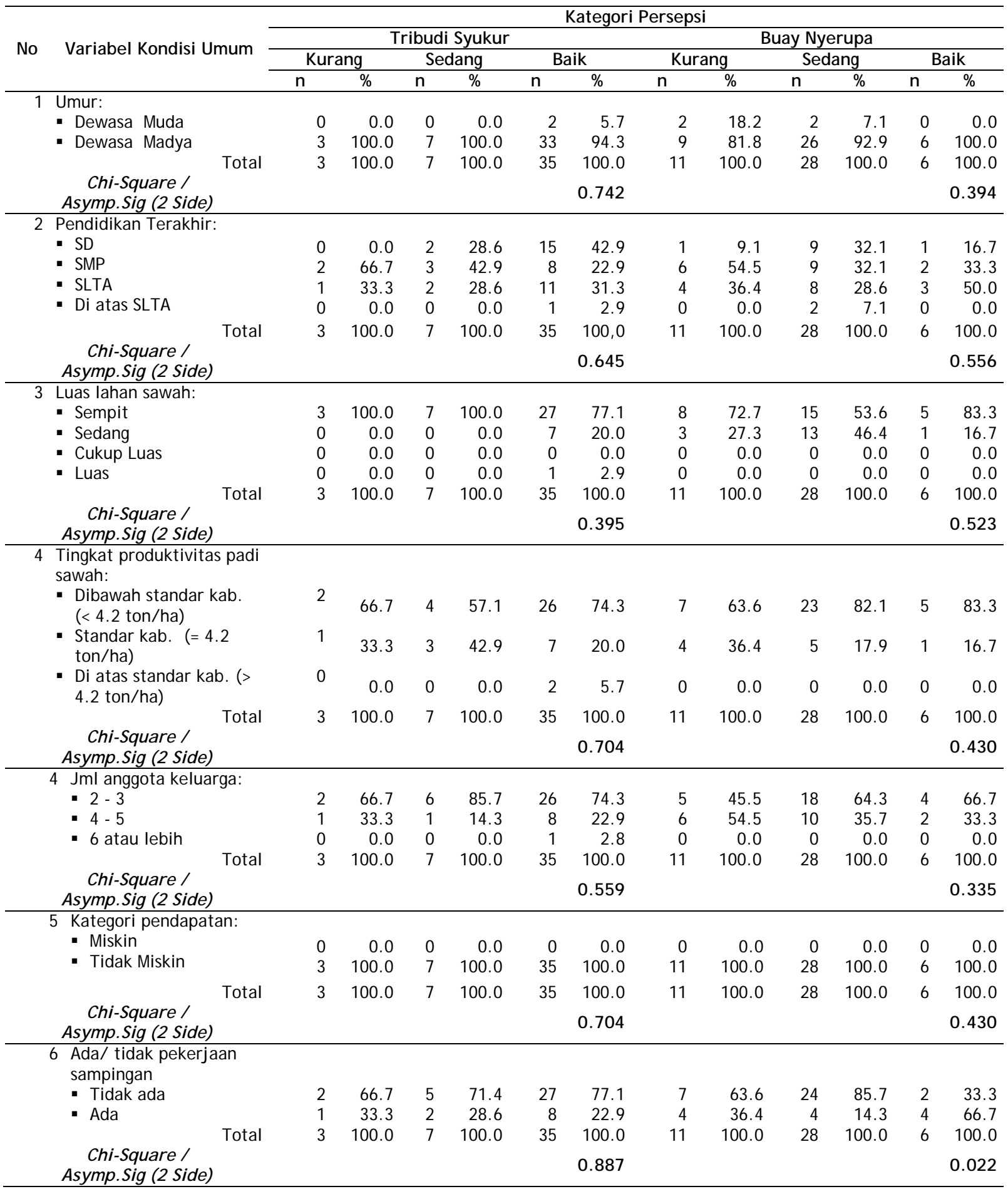

tersebut dikarenakan persepsi tentang lumbung pangan antara kedua lokasi tersebut yang berbeda, dilakukan analisis hubungan antara data persepsi dengan data partisipasi.

Analisis secara tabulasi silang dilakukan kategori persepsi dengan kategori partisipasi petani sampel di kedua lokasi penelitian. Hasil analisis untuk hubungan antara persepsi de- ngan partisipasi petani sampel tersebut sebagaimana ditunjukkan pada Tabel 6. Hasil analisis menunjukkan bahwa untuk Tribudi Syukur terdapat hubungan antara persepsi petani sampel dengan partisipasinya terhadap lumbung pangan (uji Chi-Square diperoleh nilai Asymp.Sig nya kurang dari 0.05), sedangkan di Buay Nyerupa menunjukkan bahwa antara per- 
sepsi petani sampel dengan partisipasinya terhadap lumbung pangan tidak menunj ukkan ada hubungan (uji Chi-Square diperoleh nilai Asymp.Sig nya lebih dari 0.05). Hal ini sejalan dengan yang dimaksudkan oleh Schiffman dan Kanuk (1983) bahwa persepsi yang mengandung aspek afektif yang akan menimbulkan perasaan dan emosi dalam menilai obyek tertentu yang dapat menimbulkan kecenderungan seseorang melakukan tindakan sesuai dengan yang dipersepsikan.

\section{Faktor-faktor yang Mempengaruhi Partisipasi Masyarakat dalam Kegiatan dan Pengembang- an Lumbung Pangan}

Adapun faktor-faktor yang mempengaruhi partisipasi masyarakat dalam pengembangan lumbung pangan antara lain adalah tradisi menyimpan persediaan bahan pangan oleh masyarakat, kemauan anggota masyarakat untuk membentuk kelompok (kelompok tani), persepsi masyarakat terhadap lumbung pangan, keyakinan dan harapan ingin mengembangkan lumbung pangan, keberadaan lembaga struktural pemerintah daerah di bidang ketahanan pangan, peraturan ataupun pedoman yang mendukung pengembangan lumbung pangan, program pemerintah yang mendukung pengembangan lumbung pangan, perkembangan pasar yang menyediakan bahan pangan, kondisi wilayah yang potensial rawan pangan baik kronis maupun transien.

\section{Model Lumbung Pangan dan Strategi Pe- ngembangannya secara Partisipatif}

Model lumbung pangan yang diharapkan berkembang adalah lumbung pangan modern sebagai lembaga sosial masyarakat yang dapat berfungsi meningkatkan akses pangan masyarakat maupun pelayanan dalam hal kegiatan sosial di masyarakat. Termasuk di dalam kegigiatan lumbung pangan itu adalah kegiatan simpan pinjam dalam bentuk natura, uang, ataupun sarana produksi (benih, pupuk, pestisida, dan lain-lain) untuk mendukung kegiatan usaha tani warga masyarakat yang menghasilkan bahan pangan misalnya usaha tani padi sawah, palawija dan sebagainya. Untuk menentukan strategi prioritas dilakukan analisis terhadap faktor internal dan eksternal yang mempengaruhi partisipasi masyarakat dalam pengembangan lumbung pangan melalui pembobotan, rating, dan skoring sehingga diperoleh bahwa total skor untuk faktor internal kekuatan sebesar 0.74 sedangkan total skor faktor internal kelemahan sebesar 1.75 sehingga selisih antara kekuatan dengan kelemahan sebesar -1.01. Hal tersebut sebagaimana tertera pada Tabel 7.

Pada faktor eksternal total skor peluang adalah 0.68 sedangkan total skor ancaman sebesar 2.99 sehingga selisih antara peluang dengan ancaman sebesar -2.31. Hal ini sebagaimana ditunjukkan pada Tabel 8.

Hasil akhir perhitungan analisis faktor internal dan eksternal diperoleh nilai faktor internal (X) sebesar -1.01 dan faktor eksternal (Y) sebesar -2.31. Dengan demikian bila dipetakan pada kuadran analisis SWOT adalah pada posisi kuadran IV sebagaimana gambar 1.

Berdasarkan posisi kuadran analisis SWOT dalam hal pengembangan lumbung pangan di Kabupaten Lampung Barat maka dapat diru- muskan prioritas strateginya yakni pada stra-tegi WT (mengatasi kelemahan untuk meng- antisipasi ancaman).

Adapun strategi prioritas pengembangan lumbung pangan secara partisipatif yang dapat dilaksanakan sesuai analisis SWOT meliputi:

1. Membangun persepsi masyarakat untuk tidak selalu mengandalkan pasar dalam hal akses bahan pangan.

2. Membangun persepsi dan memberdayakan partisipasi masyarakat dalam mewujudkan dan mengembangkan lumbung pangan sesuai.

Tabel 6. Hubungan antara Persepsi Petani Sampel dengan Partisipasinya terhadap Lumbung Pangan

\begin{tabular}{|c|c|c|c|c|c|c|c|c|c|c|c|c|}
\hline \multirow{4}{*}{ Kategori Persepsi } & \multicolumn{12}{|c|}{ Kategori Partisipasi } \\
\hline & \multicolumn{6}{|c|}{ Tribudi Syukur } & \multicolumn{6}{|c|}{ Buay Nyerupa } \\
\hline & \multicolumn{2}{|c|}{ Kurang } & \multicolumn{2}{|c|}{ Sedang } & \multicolumn{2}{|c|}{ Baik } & \multicolumn{2}{|c|}{ Kurang } & \multicolumn{2}{|c|}{ Sedang } & \multicolumn{2}{|c|}{ Baik } \\
\hline & $\mathbf{n}$ & $\%$ & $\mathbf{N}$ & $\%$ & $\mathbf{n}$ & $\%$ & $\mathbf{n}$ & $\%$ & $\mathbf{n}$ & $\%$ & $\mathbf{n}$ & $\%$ \\
\hline - Kurang & 3 & 23.1 & 0 & 0.0 & 0 & 0.0 & 7 & 22.6 & 3 & 37.5 & 1 & 16.1 \\
\hline - Sedang & 7 & 53.8 & 0 & 0.0 & 0 & 0.0 & 20 & 64.5 & 3 & 37.5 & 5 & 83.3 \\
\hline - Baik & 3 & 23.1 & 5 & 100.0 & 27 & 100.0 & 4 & 12.9 & 2 & 25.0 & 0 & 0.0 \\
\hline Total & 3 & 100.0 & 7 & 100.0 & 35 & 100.0 & 11 & 100.0 & 28 & 100.0 & 6 & 100.0 \\
\hline $\begin{array}{c}\text { Chi-Square / } \\
\text { Asymp.Sig (2 Side) }\end{array}$ & & & & & & 0.000 & & & & & & 0.461 \\
\hline
\end{tabular}


Tabel 7. Analisis/ Evaluasi Faktor Internal (EFI) Pengembangan Lumbung Pangan

\begin{tabular}{|c|c|c|c|c|}
\hline Faktor Internal & Bobot & Rating & Skor & Selisih \\
\hline Kekuatan (S) & & & 0.74 & \\
\hline - Keberadaan (jumlah) kelompok tani cukup baik & 0.00 & 2 & 0.00 & \\
\hline $\begin{array}{l}\text { - Adanya sebagian kelompok tani yang melaksanakan kegiatan } \\
\text { Lumbung pangan }\end{array}$ & 0.20 & 3 & 0.60 & \\
\hline $\begin{array}{l}\text { - Adanya lembaga struktural pemerintah daerah bidang } \\
\text { ketahanan pangan. }\end{array}$ & 0.07 & 2 & 0.14 & \\
\hline Kelemahan (W) & & & $\underline{1.75}$ & -1.01 \\
\hline - Persepsi masyarakat terhadap lumbung pangan belum sama & 0.27 & 3 & 0.81 & \\
\hline $\begin{array}{l}\text { - Tingkat partisipasi masyarakat dalam kegiatan lumbung } \\
\text { pangan belum sama }\end{array}$ & 0.27 & 2 & 0.54 & \\
\hline $\begin{array}{l}\text { - Tradisi masyarakat menyimpan persediaan pangan pada waktu } \\
\text { panen mayoritas masih secara individu. }\end{array}$ & 0.20 & 2 & 0.40 & \\
\hline
\end{tabular}

Tabel 8. Analisis/ Evaluasi Faktor Eksternal (EFE) Pengembangan Lumbung Pangan

\begin{tabular}{|c|c|c|c|c|}
\hline Faktor Eksternal & Bobot & Rating & Skor & Selisih \\
\hline Peluang (0) & & & $\underline{0.68}$ & \\
\hline $\begin{array}{l}\text { - Adanya peraturan sebagai pedoman pengembangan } \\
\text { lumbung pangan }\end{array}$ & 0.00 & 3 & 0.00 & \\
\hline $\begin{array}{l}\text { - Adanya program pemerintah yang mendukung } \\
\text { pengembangan lumbung pangan }\end{array}$ & 0.17 & 4 & 0.68 & \\
\hline Ancaman (T) & & & 2.99 & -2.31 \\
\hline $\begin{array}{l}\text { - Perkembangan pasar/ pedagang bahan pangan pokok } \\
\text { semakin pesat }\end{array}$ & 0.33 & 3 & 0.99 & \\
\hline - Kondisi rawan pangan bisa terjadi sewaktu-waktu & 0.50 & 4 & 2.00 & \\
\hline
\end{tabular}

3. Memelihara dan membina tradisi masyarakat berkelompok dalam mewujujudkan cadangan pangan melalui lumbung pangan.

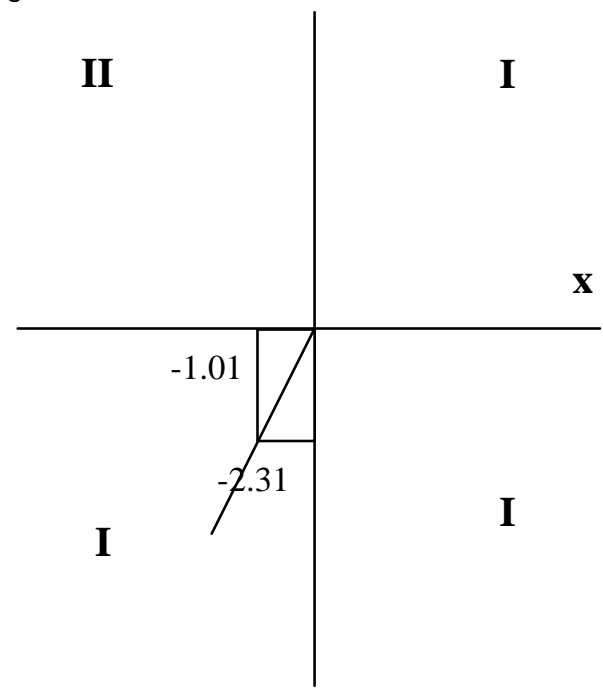

Gambar 1. Posisi Pengembangan Lumbung Pangan di Kabupaten Lampung Barat

\section{KESIMPULAN}

Kondisi persepsi masyarakat petani terhadap lumbung pangan dan hal-hal yang berhubungan dengan persepsi tersebut dapat dikatakan bahwa persepsi masyarakat petani an- tara Tribudi Syukur dengan Buay Nyerupa berbeda.

Variabel kondisi umum sampel petani tidak berhubungan dengan persepsinya terhadap lumbung pangan. Kondisi partisipasi masyarakat dalam kegiatan dan pengembangan lumbung pangan antara Tribudi Syukur dengan Buay Nyerupa berbeda.

Terdapat hubungan antara persepsi dengan partisipasi masyarakat tersebut di Tribudi Syukur, sedangkan untuk di Buay Nyerupa menunjukkan tidak ada hubungan antara persepsi dengan partisipasi terhadap kegiatan dan pengembangan lumbung pangan.

Model lumbung pangan yang diharapkan berkembang adalah lumbung pangan modern sebagai lembaga sosial masyarakat yang dapat melayani akses yang berhubungan dengan penyediaan pangan maupun pelayanan dalam hal kegiatan sosial dan ekonomi di masyarakat.

Terdapat beberapa faktor yang mempengaruhi partisipasi masyarakat dalam kegiatan dan pengembangan lumbung pangan yakni:

a. Keberadaan kelompok tani.

b. Persepsi masyarakat terhadap lumbung pangan.

c. Keberadaan dan peran lembaga struktural pemerintah daerah di bidang ketahanan pangan. 
d. Peraturan dan pedoman yang mendukung pengembangan lumbung pangan.

e. Program pemerintah yang mendukung pengembangan lumbung pangan.

f. Perkembangan pasar dan perdagangan bahan pangan.

g. Kondisi wilayah yang potensial rawan pangan baik kronis maupun transien.

Untuk mencapai lumbung pangan pada kategori modern diperlukan beberapa strategi prioritas untuk mencapainya sesuai hasil analisis SWOT terkait dengan pengembangan lumbung pangan secara partisipatif. Strategi tersebut antara lain adalah:

a. Membangun persepsi masyarakat untuk tidak selalu mengandalkan pasar dalam hal akses bahan pangan.

b. Membangun persepsi dan memberdayakan partisipasi masyarakat dalam mewujudkan dan mengembangkan lumbung pangan sesuai kondisi wilayah untuk mengantisipasi rawan pangan.

c. Memelihara dan membina tradisi masyarakat berkelompok dalam mewujudkan cadangan pangan melalui lumbung pangan.

\section{DAFTAR PUSTAKA}

Basri AS. 2006. Kearifan dan Manifestasinya pada Tokoh Lanjut Usia. Makara, Sosial Humaniora Vol. 10 No. 2. Fakultas PsikoIogi Universitas Indonesia, J akarta.

[BPS] Biro Pusat Statistik Lampung Barat. 2007. Lampung Barat Dalam Angka Tahun 2006. Badan Pusat Statistik Lampung Barat.
[BPS] Biro Pusat Statistik. 2008. Perkembangan Beberapa Indikator Utama Sosial Ekonomi Indonesia. Badan Pusat Statistik, J akarta.

[BPS dan Ditjen TP] Badan Pusat Statistik dan Direktorat Jenderal Tanaman Pangan Departemen Pertanian. 2008. Produksi, Luas Panen, dan Produktivitas Padi di Indonesia. Departemen Pertanian, J akarta.

Hutapea Y \& Bamualim A. 2004. Skala Usaha tani Padi di Beberapa Lokasi Lumbung Pangan di Sumatera Selatan. Jurnal Pengkajian dan Pengembangan Teknologi Pertanian. Vol. 7 No. $1 \mathrm{~J}$ anuari. HIm. 18-26. BPTP, Sumatera Selatan, Palembang.

[Kepmendagri No. 6/ 2001]. Keputusan Menteri dalam Negeri Nomor 6 Tahun 2001 tentang Lumbung Pangan Masyarakat Desa.

Mar'at. 1984. Sikap Manusia, Perubahan serta Pengukurannya. Ghalia Indonesia, Bandung.

Saliem HP et al. 2005. Manajemen Ketahanan Pangan Era Otonomi Daerah dan Perum Bulog. Pusat Analisis Sosial Ekonomi dan Kebijakan Pertanian - Badan Penelitian dan Pengembangan Pertanian. Departemen Pertanian, J akarta.

Schiffman, Leon G, Kanuk, \& Leslie L. 1983. Consumer Behavior, Second Edition. Prentice Hall, Inc. Englewood Cliffs. New J ersey. 